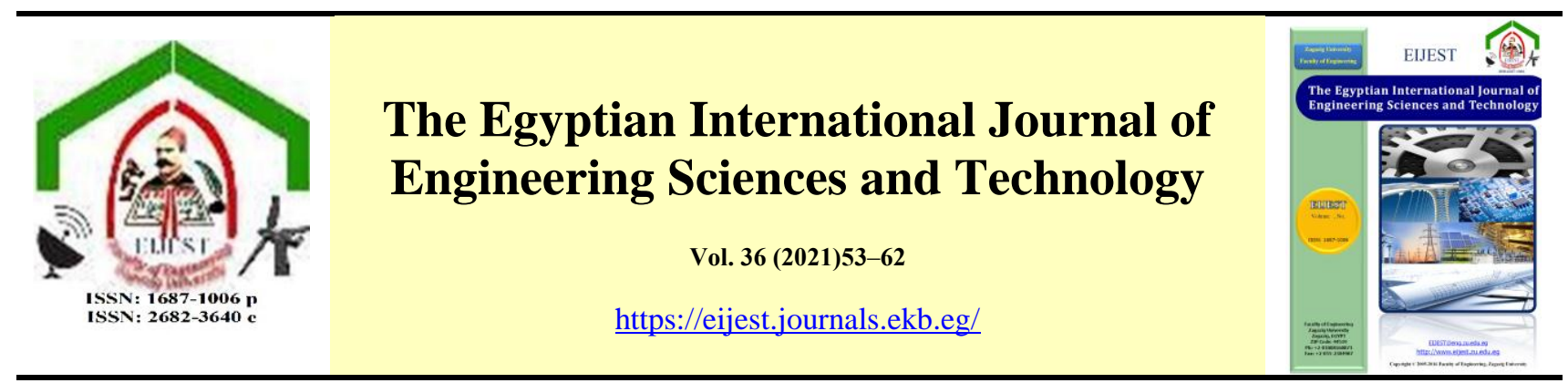

\title{
Influence of aluminum wire mesh location through stacking sequence on mechanical properties of GFRE composite laminates
}

\author{
Fatma El Zahraa Abd El-Wadoud*, Adel Fathy, Abdallah M. Kabeel, Ahmed A. Megahed
}

Department of Mechanical Design and Production Engineering, Faculty of Engineering, Zagazig University, P.O. Box: 44519, Zagazig, AlSharqia, Egypt

\begin{tabular}{|c|c|}
\hline ARTICLE INFO & A B S T RACT \\
\hline $\begin{array}{l}\text { Keywords: } \\
\text { Glass fiber } \\
\text { Aluminum wire mesh } \\
\text { Tensile test } \\
\text { Bending test } \\
\text { Hardness test }\end{array}$ & $\begin{array}{l}\text { Glass laminate aluminum reinforced epoxy (GLARE) mixes a layer of aluminum } \\
\text { with fiber-reinforced epoxy to constitute a hybrid composite. During this } \\
\text { investigation, plain E-glass fiber/epoxy specimen in addition to hybrid composite } \\
\text { laminated epoxy specimens reinforced with both E-glass fiber and wire meshes of } \\
\text { aluminum were produced. Tensile, bending, and hardness tests were performed to } \\
\text { investigate how inserting Al wire meshes through thickness of the specimen in place } \\
\text { of glass fiber layers affected the material mechanical characteristics. The } \\
\text { characteristics of the generated hybrid laminates represented by strength and } \\
\text { ductility were greatly influenced by varying the position and orienting direction of } \\
\text { the aluminum wire mesh ply. Inclusion of Al wire mesh in the outer layers } \\
\text { significantly causes deterioration in material tensile and bending strengths. The } \\
\text { tensile strain as well as bending strain, on the other hand, were improved as a result } \\
\text { of incorporating Al wire meshes by } 51.3 \text { percent and } 153.4 \text { percent respectively. }\end{array}$ \\
\hline
\end{tabular}

\section{Introduction}

Fiber strengthening, rather than other strengthening techniques, might be an interesting option for producing composites of polymer matrix with a highstrength for numerous fields of engineering [1]. Because the reinforcement in fiber strengthening is highly homogenous in all directions, the load bearing capability may be increased. Because of its multidimensional qualities, polymer composites with hybrid fiber reinforcement are in high need of engineering section.

Recently, the use of fiber reinforced PMCs (Polymeric matrix composites) in technical applications has increased dramatically. The low cost, excellent strength in addition to stiffness to weight ratios, and ease of manufacture are all arguments for using these composites [2,3].
Extremely high strength also stiffness combination yielded excellent performance in applications of space. Epoxy resins are one of thermoset materials extensively used in applications for structures due to they allow better high strength, relatively low shrinkage, excellent adhesion to various substrates, effective electrical insulation besides low in cost. Eglass fibers are acted as reinforcing material for most composites of polymer matrix because of high strength, low electrical conductivity, and also good corrosion resistance [2].

Glass-fiber reinforced polymeric composite materials (GFRPs) are used to manufacture railway locomotive body panels due to the high tensile strength and impact strength. Carbon fiber reinforced composites (CFRCs) are preferred for manufacturing automobile bonnets and fuselage in military aircraft due to its superior strength to weight ratio. Because

* Corresponding author. Tel.: +02-01062467738

E-mail address: fatmaelzahraa.abdelwadoud@yahoo.com 
of improvements in their specialized qualities, composites that are hybrids become more appealing than traditional composites. To overcome the shortage comings from metals and composite materials, the concept of integrating them into laminates, also known as hybrid composites, was made[3]. To improve torsional rigidity and stiffness, bumpers of cars are built of epoxy matrix reinforced with glass/graphite hybridizing composite.

Hybridizing metal with composite layers produces Fiber Metal Laminates (FMLs). The idea taken in one step, replacing the metal sheet with metal fiber woven mesh layers may also give or show many benefits. FMLs are made up of alternating composite layers and metal layers that are glued with each other using a suitable adhesive process [3-6]. They collaborate the benefits of composites with a fiber reinforcement also benefits of alloys of metal while avoiding the drawbacks of each alone. Aluminum is the most commonly utilized metal in FML[7].

Metal fibers, rather than a sheet, enable for the employment of production techniques similar to those used with fiber-reinforced composites (FRCs), allowing for the fabrication of more complicated structures. Metal mesh incorporation also results in inherent electromagnetic shielding capabilities of the composite thereby adding an additional functionality of the material. Because plastic deformation is a method for absorbing more energy, the capacity of the metal wire mesh to plastically deform could be advantageous in the case of an impact, as well as to postpone the perforation threshold energy [8].

Because of its distinct perfect advantages such as high performance, great specific strength (strengthto-weight ratio), and superior longevity, extensive research has been conducted in recent decades for obtaining light weight parts and structures, particularly for the military, automobile, marine, and also industries of aerospace $[9,10]$. The idea behind the application of FMLs is the combination of the suitable properties of metals and fiber reinforced composites (FRCs) [11,12]. FMLs have the potential to outperform monolithic metal alloys not only in terms of weight savings in structural component design, but also in terms of damage tolerance[11].

Commercially available FMLs are; Aramid Reinforced Aluminum (ARALL), Glass Laminate Aluminum Reinforced Epoxy (GLARE), and carbon Reinforced Aluminum Laminates (CARALL) found in the same hierarchy. ARALL was discovered in which aramid fibers prepreg are used with aluminum sheet metal. Further research led to the development of GLARE, which is made up of multiple extremely tiny layers of metal (typically aluminum) interlaced with many layers of glass-fiber "prepreg" that are linked conjointly with the matrix of an epoxy. Gave better results than ARALL, thus it is most widely used FML.CARALL, a material that uses carbon fibers and has outstanding results in all tests, was created in recent years, but difficulties with metallic reactions with carbon fiber caused instability in the material. As a result, when compared to other FMLs, GLARE is the greatest alternative with better attributes [3].

GLARE is a modernistic classification of FMLs with good mechanical properties such as a high tensile strength, outstanding fatigue, impact resistance, in addition to excellent corrosion properties. GLARE has been extensively used in advanced aerospace and automobile industries[6,8]. It has been applied to structures the fuselage skin of commercial aircrafts as Airbus A380 [13,14]. Different types of stress risers, such as holes at riveted and bolted joints, grooves, and corners, are frequently found in structural components in aircraft and general transportation applications. This meant that the materials used to make those structural parts had to be able to withstand high levels of fatigue and damage in notched configurations[13].

As a result, GLARE will be used in a wider range of applications, including aircrafts construction and constituents for transportation which requires more information about the ability of notched GLARE laminates damage tolerance. GLARE parts are constructed and repaired using mostly traditional metal material techniques. Over an aluminum alloy, the mechanistic qualities of the lamination of GLARE through the fiber result in weight loss [10].

Ahmed et al. [13] stated that E-glass fiber reinforced epoxy laminates are used to make the majority of aircraft parts. Nonetheless, using of metal fiber wire mesh rather than sheet metal in FML composites provides the prospect for increasing mechanistic qualities as well as the numerous manufacturing procedures used to create fiberreinforced composites. Using metal fiber mesh in place of sheet of metal in FMLs, on the other hand, has the potential to improve mechanistic properties while also allowing for a wider range of production techniques for composites with fiber reinforcement.

Karunagaran and Rajadurai [2] demonstrated the mechanical characteristics of the composite that is hybrids constructed with a treated surface of glass fiber and also treated surface of stainless-steel wire 
mesh were 20 to 30 percent better than those of glass fiber-reinforced polymer composites.

Ghamarian et al. [15] investigated the tensile characteristics of laminated composites in various orientations and discovered that the layer orientation is crucial in choosing the optimal property for further application.

Prakash and Julyes [1] investigated mechanical strength behavior for E-glass fiber with a silane treatment, Aluminum 6061 and also stainless steel 304 wire meshes reinforced epoxy resin hybrid composite materials. They found that a composite made of modifying surface Stainless Steel-304 wire mesh and E-glass fiber had highest tensile as well as bending strengths.

Wilk and Śliwa [16] investigated the effect of aluminum alloys 2024, 6061, in addition to 7075 on the ultimate characteristics of type of GLARE composite materials. Also, they discovered that GLARE-type composites constructed of 7075 alloy sheets had the best mechanistic characteristics when compared with composites made of 2024 and 6061 sheets.

Xie et al. [17] investigated the impact due to notch geometrical properties such as notch shape, notch size, besides off-axis angle on the tension testing of GLARE composite laminate with circular notches in addition to square notches. Also, they discovered that the strength of the square notched laminate is roughly equivalent to that of the circumscribed circle notch laminate. As the square notch's corner radius grows, the delamination damage region grows as well.

In this study, Using the hand lay-up technique, pristine E-glass fiber specimens as well as specimens including laminates of both E-glass fiber and $\mathrm{Al}$ wire meshes were made by varying the placement of $\mathrm{Al}$ wire mesh laminates inside the created plies. The influence of including $\mathrm{Al}$ wire mesh in various locations inside the specimen in place of glass fiber layers on the mechanical behavior of the fabricated specimens was investigated using tensile, bending, and hardness tests.

\section{Material Specification}

In this study E-Glass fiber woven roving mat, commercial Aluminum (Al) Wire mesh (6061 alloy), and epoxy resin were selected for manufacturing of specimens. Glass fiber woven roving having (45/-45) and (0/90) orientations were used for the manufacturing process. Glass fiber was selected as it is the most commonly used reinforcement in polymer due to its toughness, energy absorption and strength.
The matrix phase for the composite specimens was epoxy resin (kemapoxy RGL 150) and the hardener of it known as (cycloaliphatic amine "di-functional primary amine") provided from Chemicals for Modern Buildings international company-Egypt. epoxy and the hardener of epoxy were mixed at a 2:1 weight ratio, as advised by the manufacturer, and the mixture was agitated constantly with a hand-held stirrer up til a well-mixed mixture was created. Aluminum wire meshes with diameter of $0.29 \mathrm{~mm}$ and $0.63 \mathrm{mesh} / \mathrm{mm}$ were supplied by ELGOHARY Company, Egypt.

\section{Experimental Procedure}

\subsection{Specimen manufacturing}

All of the hybrid composite specimens that were produced had a number of eight plies. As shown in Fig. 1(b), the plies were stacked in an alternate lamination sequence, forming the $[(0 / 90)(45 /-45)$ (0/90) (45/-45)]s stacking arrangement.

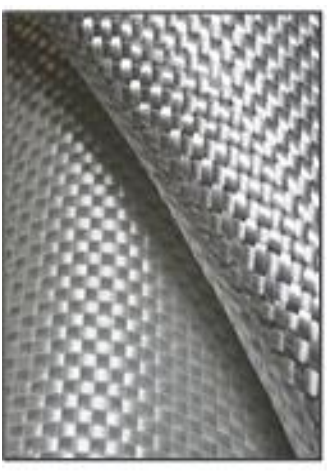

Glass fiber

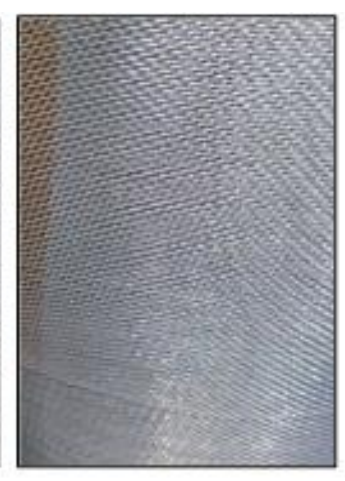

Al mesh (a) Raw materials

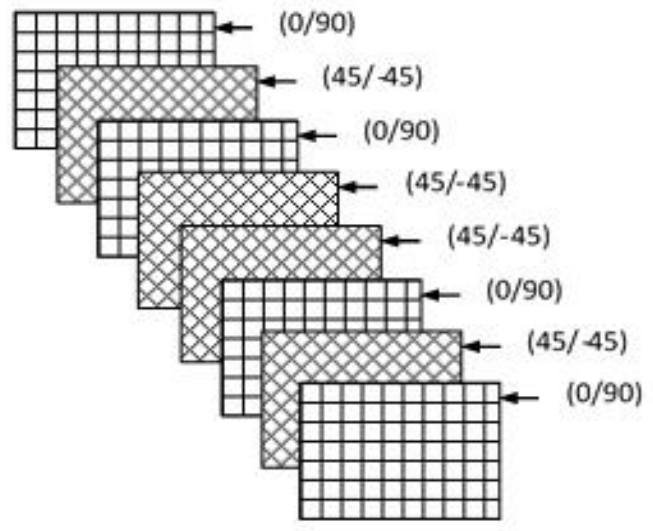

(b) Lay-up process

Fig. 1. Materials and the laminate stacking sequence arrangement. 
Aluminum wire meshes were treated before preparation of specimens' laminate. The process was performed using an alumina $\left(\mathrm{Al}_{2} \mathrm{O}_{3}\right)$ emery paper with grade 400 to grind both sides of the $\mathrm{Al}$ mesh to treat the surface uniformly since treated surface assists in improved adhesion between mating surfaces [18]. The meshes were then immersed in acetone for 10 minutes to clear away any trash and chips. The Al wire meshes were then dehydrated by using air compressing at a standard ambient temperature. to get rid of any trash and chips.

The hybrid composite plates were made using the hand lay-up technology process. It can be explained as follows; First, a flat surface (glass sheet) was coated with releasing agent (paraffin wax) to facilitate the removal of the composite plate after curing. After that, a suitable amount of epoxy was placed over the glass sheet and distributed roughly using a roller. Second, the first layer of the stack sequence (according to Table 1) was placed. A suitable amount of epoxy was added over this layer and a roller was used to distribute it to ensure the saturation of fibers with epoxy. The same process was repeated until the whole stack sequence was done. Finally, a flat surface (glass sheet coated with paraffin wax) was placed over the laminates [17,19]. Weights of $45 \mathrm{~kg}$ were placed over the laminates for 24 hours at room temperature for curing. Then, the weights were removed and the specimen were taken and put over a flat surface for post curing period of 21 days at room temperature. Then, specimens were prepared to cut into standard test dimensions. The thickness of the produced specimens was $2 \pm 0.1 \mathrm{~mm}$ for plain glass fiber (PG) layers, $2.5 \pm 0.15 \mathrm{~mm}$ for laminates with two layers of $\mathrm{Al}$ mesh, A1A8, A2A7, $\mathrm{A} 3 \mathrm{~A} 6$, and A4A5. The Al wire mesh was inserted through various thickness places, according to Table 1 , in order to determine where the most useful contributions can be made. The steps of the manufacturing process are illustrated in Fig. 2.

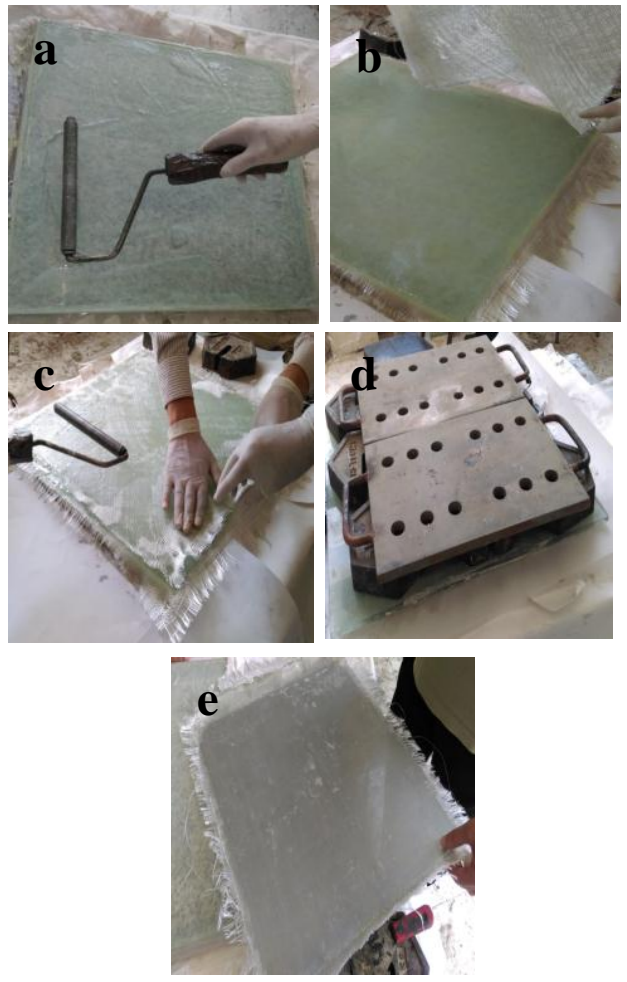

Fig. 2. Steps for specimens manufacturing

Table 1. Stacking sequences of produced specimens

\begin{tabular}{|c|c|}
\hline Specimen & Configuration of fiber and metal \\
\hline PG & {$[(0 / 90),(45 /-45),(0 / 90),(45 /-45)] \mathrm{s}$} \\
\hline A1A8 & {$[\mathrm{Al}(0 / 90),(45 /-45),(0 / 90),(45 /-45)] \mathrm{s}$} \\
\hline A2A7 & {$[(0 / 90), \mathrm{Al}(45 /-45),(0 / 90),(45 /-45)] \mathrm{s}$} \\
\hline A3A6 & {$[(0 / 90),(45 /-45), \mathrm{Al}(0 / 90),(45 /-45)] \mathrm{s}$} \\
\hline A4A5 & {$[(0 / 90),(45 /-45),(0 / 90), \mathrm{Al}(45 /-45)] \mathrm{s}$} \\
\hline
\end{tabular}

G: Glass fiber

A: Aluminum mesh 


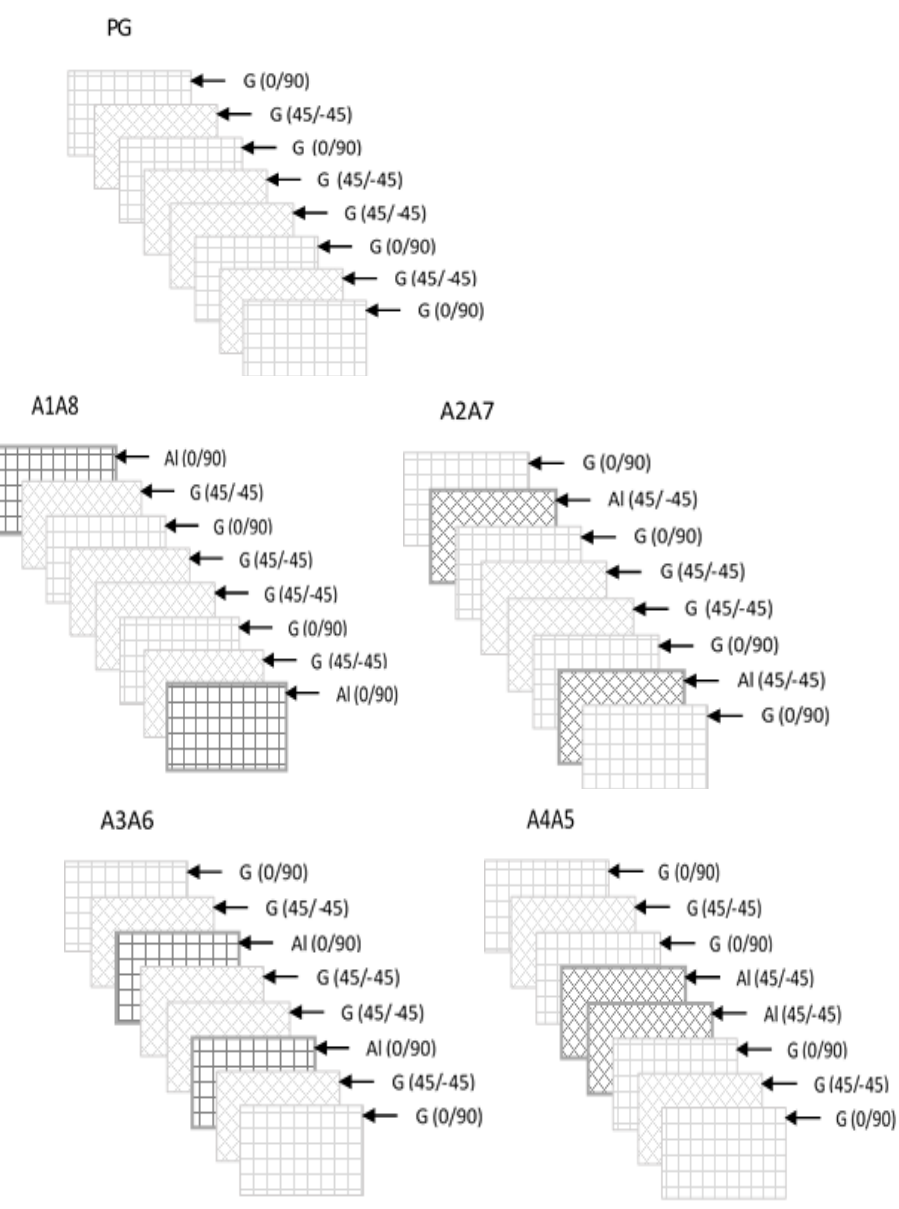

Fig. 3. Schematic diagram of the structure and designation of the manufactured laminates

\subsection{Mechanical tests}

\subsubsection{Tension test}

Tensile testing was carried out at room temperature using an ASTM D3039-compliant computerized universal testing equipment (Jinan Testing Machine-WDW of $100 \mathrm{KN}$ ). In accordance with ASTM D3039. A cross-head is adjusted to a speed with a value of two $\mathrm{mm} / \mathrm{min}$. Specimen test was nominally $210 \mathrm{~mm} \times 27 \mathrm{~mm}$ in dimension. The average of the five tests was used to calculate tensile strength and strain. The tensile modulus of elasticity, E, was calculated using an average of the five samples as sloping of the linear response of the tensile stress-tensile strain curve.

\subsubsection{Bending test}

A three-point bending tests were performed, at room temperature using a computerized universal testing equipment (Jinan Test Machine WDW 100 $\mathrm{kN}$ ) with a cross head speed of $1 \mathrm{~mm} / \mathrm{min}$. within a size of $100 \mathrm{~mm} \times 15 \mathrm{~mm} 2$, test specimens were prepared from the laminate in accordance with ASTM D-790. The average of five tested samples was used to determine the bending strength of each type of laminate.

\subsubsection{Hardness test}

Barcol hardness of the manufactured specimens was measured using PCE-1000N device. The measurements were taken randomly at ten different positions of each specimen. The minimum and maximum readings were discarded. The hardness value of a typical specimen was taken as the mean value of the remaining eight readings.

\section{Results and Discussion}

\subsection{Tensile properties}

Figure 4 illustrates relationship of tensile stress and strain for all the fabricated specimens. According to the figure, it is noted that, PG specimen laminate gives the best tensile strength among all specimens of 190.9 $\mathrm{MPa}$, and specimen A3A6 has the minimum value of strength of about 89.9 MPa. However, specimen A1A8 has the highest strain with a value of 0.109, while specimen A4A5 gives the lowest value of strain of about 0.065. Furthermore, specimens A2A7 and A4A5 show the same attitude of sudden or brittle failure characteristics.

Figure 5 illustrates a comparison of tensile strengths of all manufactured laminates. From the figure it is clear that, in comparison to all specimens that have aluminium laminates, PG exhibits the highest tensile strength. This is owing to the fact that fiber glass has a higher tensile strength than $\mathrm{Al}$ wire mesh. Incorporation of aluminum laminates as an alternative for a certain glass fiber causes degradation in tensile strength this is due to the inadequate connection between the neighbouring layers of fiber glass and aluminium. From fig 5, It is observed that, samples A1A8 and A3A6, with a lamina of Al mesh 
directed at (0/90), have less strength in comparison with samples, A2A7 and A4A5, have an Al wire mesh lamina with an orientation of (45) and (- 45). The poor strength of the A1A8 laminate is due to the replacement of oriented (0/90) glass fiber with orientation (0/90) Al wire mesh ply; however, for the A4A5, glass fibre was replaced with $\mathrm{Al}$ wire mesh at the $(45 / 45)$ ply. The load carrying capacity of $0^{\circ}$ plies is greater than $45^{\circ}$ or $-45^{\circ}$, resulting in a higher drop in strength when the $0^{\circ}$ fibre glass layer is replaced with $\mathrm{Al}$ mesh [1].

Prakash and Jaisingh [1] recorded a decrease in tensile strength of $10 \%$ and $17.5 \%$ for composite specimens containing as-received steel and aluminum metal wire meshes respectively, compared with plain fibre glass reinforced epoxy specimen. The addition of steel and aluminium wire meshes, as well as Eglass fibre, to epoxy resin reduced its load-sharing ability, resulting in lower tensile strength. The poor adherence of metal wire meshes to E-glass fibre and epoxy resin matrix results in decreased tensile strength.

Comparison of the tensile strains for the produced manufactured composite specimens is shown at Fig. 6. The figure demonstrates that, specimen A1A8 has the highest strain among all the produced specimens, with an improvement of $51.3 \%$ in the tensile strain above PG specimen. Also, A3A6 specimen shows an improvement of about $11.2 \%$ in the tensile strain compared with PG specimen. Replacement of glass fiber lamina by an aluminum wire mesh increased the ductility of the specimen due to the intrinsic ductility of aluminum as compared with that of E-fibre glass and hence an increase of its strain is achieved.

Figure 7 shows both local and global. Scanning Electron Microscope photos of PG and A4A5 specimens as a good example of laminates that hybrids. The glass fiber breakage, delamination and debonding are the principal deterioration mechanisms in the PG specimen as displayed in Fig. 7 (a) and (b). a type of new damage mechanism arises in specimen $\mathrm{A} 4 \mathrm{~A} 5$, which is the ductile fracture of $\mathrm{Al}$ wire mesh, as seen in Fig. 7 (c) and (d).

The strength and strain of specimens A2A7 and A4A5 are moderately correlated. According to these findings, the position and orientation of the $\mathrm{Al}$ wire mesh in hybrid composite laminates has a significant impact on the strength and strain. The tensile strength of the laminate is relatively improved when $\mathrm{Al}$ wire mesh is positioned at (45/-45) orientation compared with positioning at $(0 / 90)$ orientation. In addition, replacing E-glass fibres aligned at $0^{\circ}$ and $90^{\circ}$ with wire mesh of $\mathrm{Al}$ has less impact than substituting glass fibres with an orientation of $45^{\circ}$ and $-45^{\circ}$.

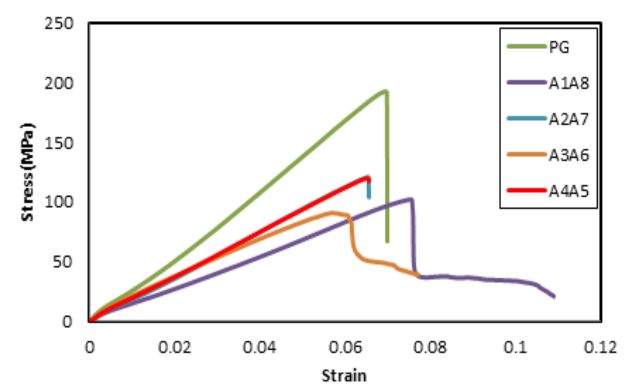

Fig. 4. Tensile stress-strain diagrams of manufactured hybrid laminates

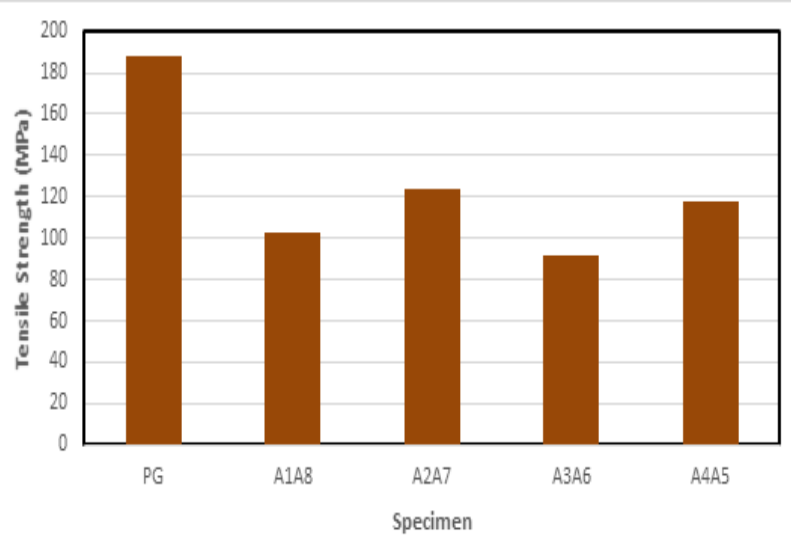

Fig. 5. Tensile strength of the manufactured laminates.

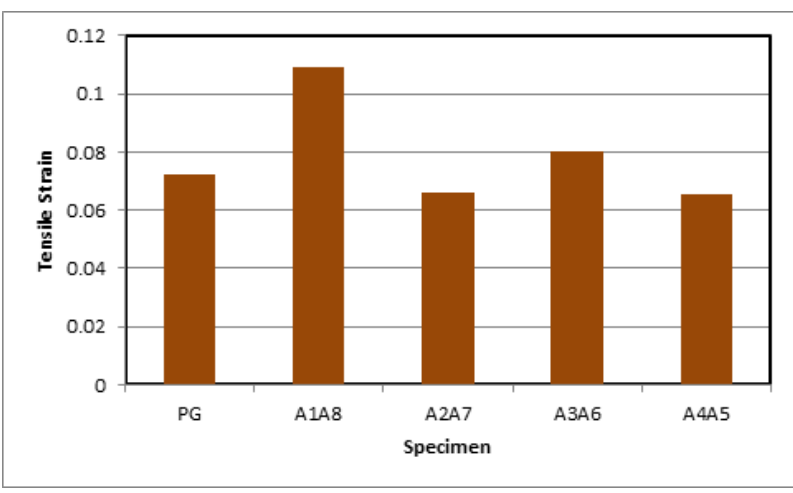

Fig. 6. Tensile strain of all the manufactured hybrid laminates. 

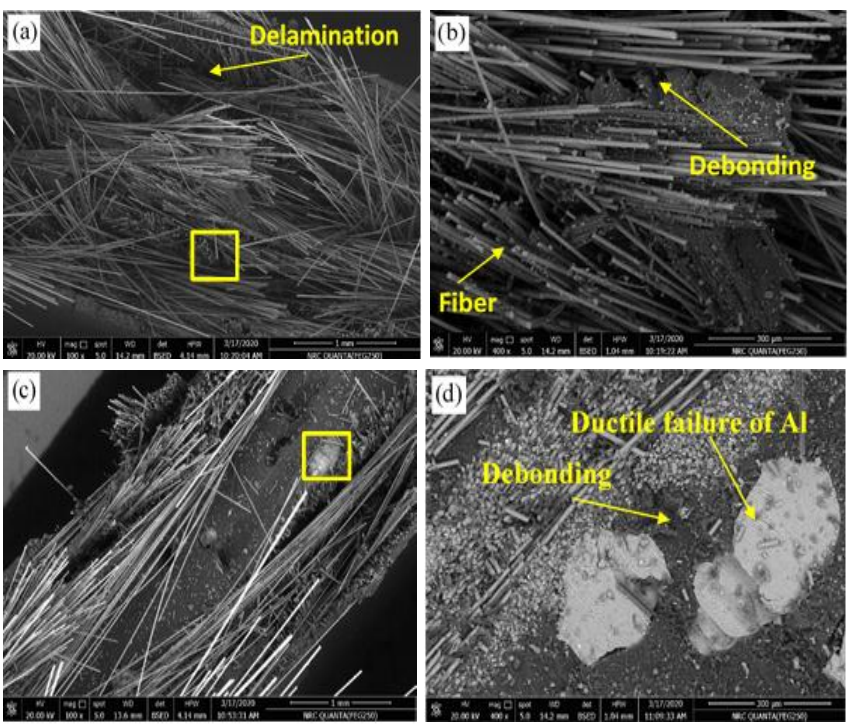

Fig. 7. Scanning Electron Microscope microphotographs image of; (Fig. a and Fig. b) PG specimen and (Fig. c and Fig. d) A4A5 specimen.

Fig. $b$ and Fig. $d$ are enlarged view of the red rectangles in Fig. a and Fig. c, respectively.

The tensile elastic modulus of elasticity for all fabricated laminate specimens are shown in Fig. 8. When compared to all specimens that comprise layers of aluminium wire mesh, it is obvious that PG has the highest tensile modulus as illustrated in Fig. 8. Because of the strong bonding between the fibre glass laminates in the PG specimen, the specimen is more rigid, resulting in a relatively high tensile elastic modulus. Furthermore, the inclusion of $\mathrm{Al}$ wire meshes at the laminate's first and last layers, as the case of A1A8 specimen, causes more debonding and permits for more deformation at relatively low stress, resulting in a decrease in elastic tensile modulus.

For specimens containing $\mathrm{Al}$ wire mesh, incorporation of $\mathrm{Al}$ wire mesh oriented at (45/-45) makes an enhancement in elastic modulus than incorporation of $\mathrm{Al}$ wire mesh at (0/90) orientation. However, presence of $\mathrm{Al}$ wire mesh at the inner layers at (0/90), A3A6 specimen, improved elastic modulus by $18.7 \%$ as compared to Al wire mesh positioned at the outer (0/90) layer, A1 A8 specimen. On the other hand, onset of $\mathrm{Al}$ wire mesh at (45/-45) near the outer layers, A2A7 specimen, tends to give a relatively higher value of tensile modulus (about $6.2 \%$ higher) than if $\mathrm{Al}$ wire mesh positioned near the core of the specimen at (45/-45), A4A5 specimen.

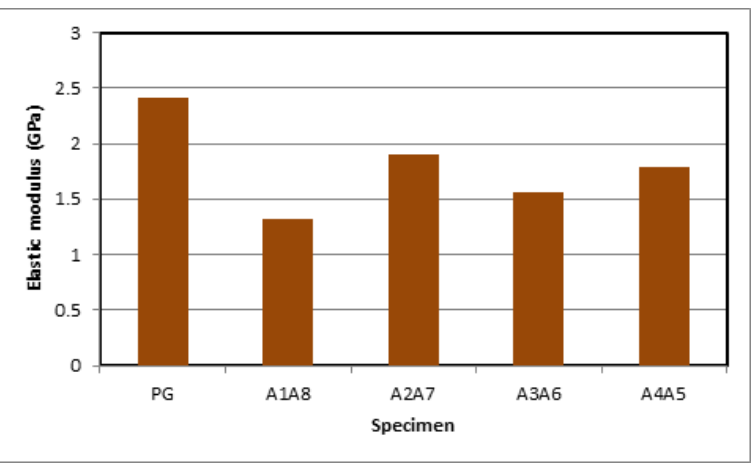

Fig. 8. Tensile Elastic modulus of the produced laminates

\subsection{Bending properties}

The bending stress and bending strain relationship for all produced fabricated specimens is seen in Fig. 9. Moreover, comparison among bending strengths of all the fabricated specimen laminates is shown in Fig. 10. From these figures it is clear that, specimen PG has the maximum bending strength of $185.2 \mathrm{MPa}$, while A1A8 specimen has the minimum strength in bending with in a value of $60.7 \mathrm{MPa}$. Specimen A1A8 has the maximum bending strain, while A4A5 specimen gives the minimum value of bending strain and brittle failure. The bending reaction is identical to the tensile testing, as shown in Fig. 4.

This behaviour is owing to an excellent bonding between the glass-fiber laminates for the PG specimen, as mentioned in section 3.1. Due to the comparatively poor bonding between the adjacent plies of glass fiber and aluminium, including aluminium wire meshes within glass fiber laminates reduces bending strength. Because of aluminium wire meshes have no chemical bond with epoxy resin, no load can be transmitted from the matrix to the reinforcements. However, because $\mathrm{Al}$ wire mesh layers are placed on the specimen's outer surfaces, the A1A8 specimen has a low bending strength. Where the largest normal and shear loads occur at the first and last layers of the laminates, respectively [20,21], the inclusion of Al wire mesh with low 
adhesion bonding with epoxy at the outer layers leads to earlier damage initiation and hence reduced bending strength.

Figure 11 illustrates bending strain of all fabricated specimens. According to figure 11, specimen A1A8 gives the highest bending strain as compared to other produced fabricated specimens, with an improve of $153.4 \%$ above PG specimen. Replacement of fibre glass lamina by an aluminum one increased the ductility of the specimen due to the intrinsic ductility of the aluminum which causes ductile failure during bending test and postpones the complete failure of the laminate hence an increase of its bending strain is obtained. Furthermore, all specimens with $\mathrm{Al}$ wire mesh layers, with the exception of A4A5 specimen, show a larger bending strain than PG specimens, Fig. 11. During the bending test, two $\mathrm{Al}$ wire mesh layers in the A4A5 specimen are situated in the middle of the laminates, close to the neutral axis of the specimen, therefore there was no improvement in bending strain due to positioning the aluminium layers in the middle .Moreover, Except for A4A5, all specimens with $\mathrm{Al}$ wire meshes show a higher bending strain than plain glass-fiber (PG) specimen., as shown in Fig. 11, this is due to the composition of two successive Al lamina in A4A5 specimen where bonding between metal laminates is very poor compared to bonding between either fiber laminates or fiber and metal laminates.

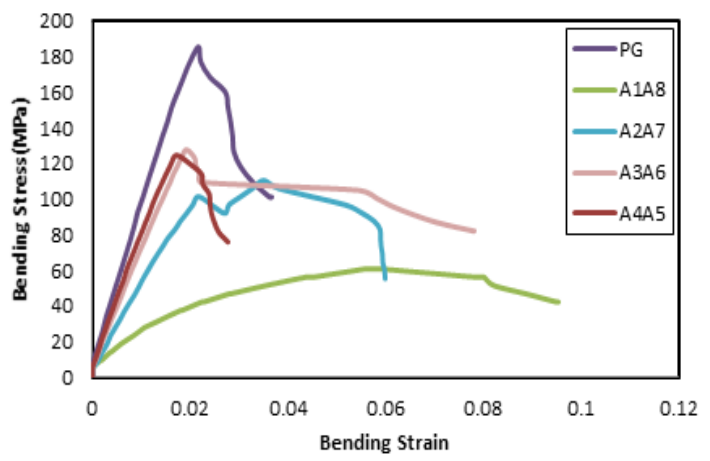

Fig. 9. Bending stress- strain diagrams of generated manufactured laminates.

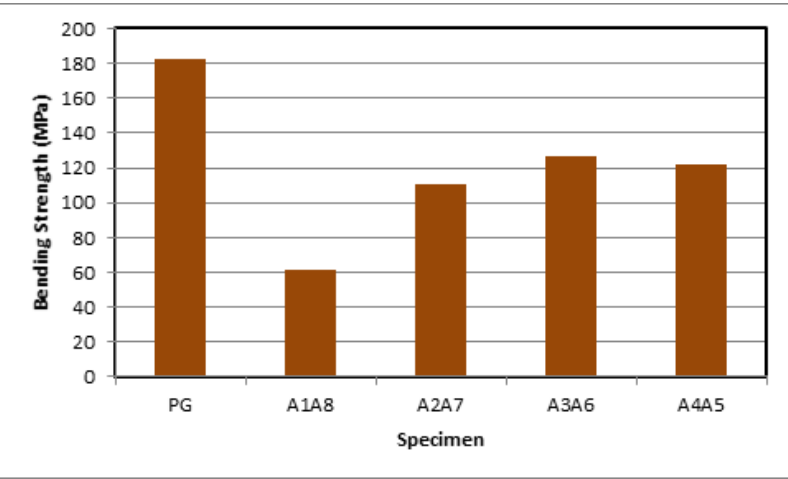

Fig. 10. Bending strength of the produced hybrid laminates.

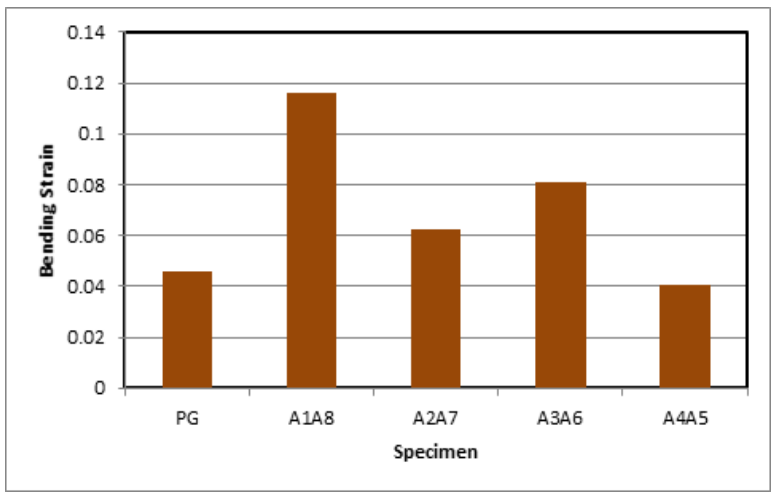

Fig. 11. Bending strain for plain and GLARE specimens

Bending modulus of fabricated laminate specimens are presented in Fig. 12. Comparing all manufactured specimens with aluminium layers, PG has the highest bending modulus as in fig 12. Because of the strong bonding between the fibre glass laminates in the PG specimen, the specimen is stiffer, resulting in a relatively high bending modulus. Because of the inclusion of $\mathrm{Al}$ wire meshes at the outer ply of the specimen, which is exposed to greatest shear stresses due to compression and thus earlier damage onset, the A1A8 specimen had the lowest bending modulus. As a result, the inclusion of $\mathrm{Al}$ wire meshes at the outer layers leads to a considerable deterioration in the elastic modulus in terms of stiffness.

For specimens containing $\mathrm{Al}$ wire mesh, it is noticeable that bending modulus increases gradually by approaching into the core of specimen. Presence of $\mathrm{Al}$ wire mesh at inner layers at (0/90) orientation, as in A3A6 specimen, leads to better bending modulus compared to positioning $\mathrm{Al}$ wire mesh at 
outer layers at (0/90) as in A1 A8 specimen. Also, specimen A2A7 has lower bending modulus than A4A5 specimen, as a result of presence of $\mathrm{Al}$ mesh near outer layers at (45/-45) compared to its presence at the same orientation, (45/-45), at the core of A4A5 specimen.

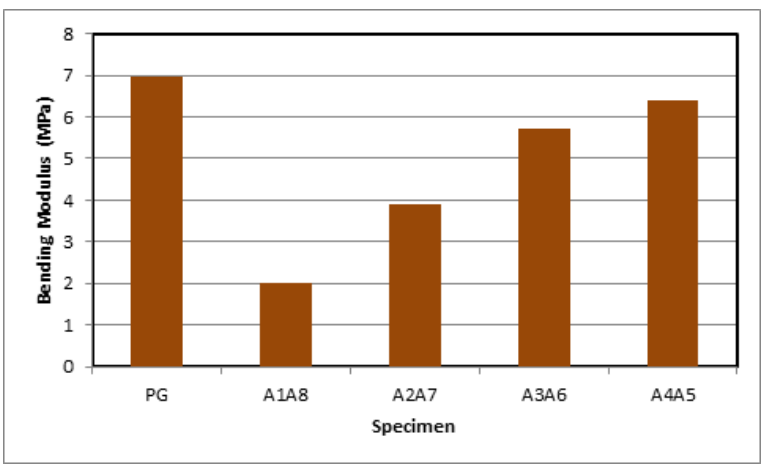

ig. 12. Bending modulus for all fabricated specimens

\subsection{Hardness properties}

The results of the hardness test are depicted in Table 2. The results indicate that, specimens that have glass fiber lamina in their outer layer (PG, A2A7, A3A6 and A4A5) show approximately the same hardness value that are higher than specimen with the aluminum wire mesh positioned at the outer layer (A1A8 specimen). This behavior may be attributed to the higher value of the hardness of glass fiber (about $450 \mathrm{~kg} / \mathrm{mm}^{2}$ [22]) as compared to that of 6061 aluminum $\left(95 \mathrm{~kg} / \mathrm{mm}^{2}\right.$ [23]). Therefore, when the outer layer of the specimen which is the first layer in contact with the indenter of the hardness measuring instrument is glass fiber, the resulting measurement of hardness will be high (Barcol 71.07 on average). On the other hand, if the aluminum wire mesh is the outer lamina of the specimen, a deterioration in hardness will be observed (Barcol 41.69).

Table 2. Hardness values for the fabricated laminates

\begin{tabular}{|c|c|}
\hline Specimen & Hardness (Barcol) \\
\hline PG & 72.40 \\
\hline A1A8 & 41.69 \\
\hline A2A7 & 68.48 \\
\hline A3A6 & 71.21 \\
\hline A4A5 & 72.18 \\
\hline
\end{tabular}

\section{Conclusions}

During the current study, plain E-glass fiber/epoxy composite specimens in addition to hybrid specimens with E-glass fibers/epoxy and $\mathrm{Al}$ wire meshes were fabricated. The influence of inserting Al wire meshes at various positions through stacking thickness of the specimen on the mechanical attitude of the fabricated specimens was investigated using tensile, bending, and hardness tests.

The following is a summary of the findings:

1- When Al wire mesh is used to replace some of the glass fiber plies, the tensile strength suffers as a result of the relatively weak bond between the adjacent plies of glass fiber and aluminum wire mesh..

2- Specimen A1A8 has the maximum tensile strain among all of the fabricated specimens, with an improvement of $51.3 \%$ in the tensile strain above PG specimen. Also, A3A6 specimen shows an improvement of about $11.2 \%$ in the tensile strain compared with PG specimen.

3- In comparison to all laminates containing an $\mathrm{Al}$ mesh layer, the plain fiber glass specimen offers the maximum bending strength. Bending strength is reduced when aluminum layers are incorporated into fiber glass layers. The largest bending strain improvement was 153.4 percent in specimen with aluminum wire mesh positioned at the outer plies, A1A8 laminate.

4- Specimens that have fiber glass lamina in their outer layers (PG, A2A7, A3A6 and A4A5) show approximately the same hardness value that are higher than specimen with the aluminum wire mesh located at the outer layers (A1 A8 specimen).

\section{References}

[1] V. R. A. Prakash and S. J. Jaisingh, "Mechanical Strength Behaviour of Silane Treated E-glass Fibre / Al 6061 \& SS304 Wire Mesh Reinforced Epoxy Resin Hybrid Composite," pp. 2279-2286, 2018.

[2] N. Karunagaran and A. Rajadurai, "Effect of surface treatment on mechanical properties of glass fiber/stainless steel wire mesh reinforced epoxy hybrid composites," J. Mech. Sci. Technol., vol. 30, no. 6, pp. 2475-2482, 2016, doi: 10.1007/s12206-016-0507-9.

[3] N. A. Patil, S. S. Mulik, K. S. Wangikar, and A. P. Kulkarni, "ScienceDirect ScienceDirect ScienceDirect Characterization of Glass Laminate Aluminium Reinforced Epoxy- 
Characterization of Glass Laminate Aluminium Reinforced Epoxy- A Review India Trade-off Costing models for capacity optimization in Industry and opera," Procedia Manuf., vol. 20, pp. 554-562, 2018, doi: 10.1016/j.promfg.2018.02.083.

[4] T. Subesh, D. Yogaraj, and V. Ramesh, "Characterization of fiber metal laminates, bonding and manufacturing methods," Int. J. Innov. Technol. Explor. Eng., vol. 8, no. 11, pp. 10621065, 2019, doi: 10.35940/ijitee.J1117.0981119.

[5] N. K. Romli et al., "The behavior of Aluminium Carbon/Epoxy fibre metal laminate under quasi-static loading," IOP Conf. Ser. Mater. Sci. Eng., vol. 257, no. 1, 2017, doi: 10.1088/1757-899X/257/1/012046.

[6] A. K. McBride, S. L. Turek, A. E. Zaghi, and K. A. Burke, "Mechanical Behavior of Hybrid Glass/Steel Fiber Reinforced Epoxy Composites," Polymers (Basel)., vol. 9, no. 4, 2017, doi: 10.3390/polym9040151.

[7] F. D. Morinière, R. C. Alderliesten, M. Sadighi, and R. Benedictus, "An integrated study on the low-velocity impact response of the GLARE fibre-metal laminate," Compos. Struct., vol. 100, pp. 89-103, 2013, doi: 10.1016/j.compstruct.2012.12.016.

[8] A. M. Kadhum, S. T. Faris, and A. A. Al-Katawy, "Development and Properties of Fiber Metal Laminate Used in Aircraft Wing by Using Epoxy-Novolac," IOP Conf. Ser. Mater. Sci. Eng., vol. 518, no. 3, 2019, doi: 10.1088/1757899X/518/3/032034.

[9] S. Liu, L. Lang, E. Sherkatghanad, Y. Wang, and W. Xu, "Investigation into the Fiber Orientation Effect on the Formability of GLARE Materials in the Stamp Forming Process," Appl. Compos. Mater., vol. 25, no. 2, pp. 255-267, 2018, doi: 10.1007/s10443-017-9615-7.

[10] K. Logesh, V. K. Bupesh Raja, V. H. Nair, K. M. Sreerag, K. M. Vishvesvaran, and M. Balaji, "Review on manufacturing of fibre metal laminates and its characterization techniques," Int. J. Mech. Eng. Technol., vol. 8, no. 10, pp. 561-578, 2017.

[11] R. Senthilkumar, A. Senthilkumar, and V. Ashamelba, "Processing of 45-degree Stitched Mat GLARE Laminate and Analyzing Tensile and Flexural Properties," vol. 7, no. 2, pp. 54-62, 2014.

12] A. Thirumurugan et al., "Investigations on aluminium wire mesh, banana fiber and glass fiber reinforced hybrid composites," Indian J. Sci. Technol., vol. 9, no. 42, 2016, doi: 10.17485/ijst/2016/v9i42/103306.
[13] T. J. Ahmed, H. E. N. Bersee, and A. Beukers, "Low velocity impact on woven glass compoistes reinforced with metal mesh layers," ICCM Int. Conf. Compos. Mater., pp. 1-6, 2007.

[14] M. Kawai and T. Sato, "OFF-AXIS NOTCHED FATIGUE BEHAVIOR OF FIBER METAL LAMINATE GLARE-3," vol. 15, no. June, pp. 24-28, 2012.

[15] N. Ghamarian, M. A. Azmah Hanim, P. Penjumras, and D. L. Majid, Effect of Fiber Orientation on the Mechanical Properties of Laminated Polymer Composites. Elsevier Ltd., 2016.

[16] M. S. Wilk, "The influence of features of aluminium alloys 2024, 6061 and 7075 on the properties of glare-type composites," 1982, doi: 10.1515/amm-2015-0496.

[17] B. Xie, L. Gao, S. Jiang, S. Zhang, and C. Wu, "Notched tensile response and damage mechanism of the GLARE laminate," 2020, doi: 10.1177/0021998320907963.

[18] M. Megahed, A. A. Megahed, and M. A. Agwa, "The influence of incorporation of silica and carbon nanoparticles on the mechanical properties of hybrid glass fiber reinforced epoxy," J. Ind. Text., vol. 49, no. 2, pp. 181-199, 2019, doi: $10.1177 / 1528083718775978$.

[19] M. A. Agwa and A. A. Megahed, "New nonlinear regression modeling and multi-objective optimization of cutting parameters in drilling of GFRE composites to minimize delamination," Polym. Test., vol. 75, no. February, pp. 192 204, 2019, doi: 10.1016/j.polymertesting.2019.02.011.

[20] A. Wagih, P. Maimí, N. Blanco, and J. Costa, "A quasi-static indentation test to elucidate the sequence of damage events in low velocity impacts on composite laminates," Compos. PART A, 2015, doi: 10.1016/j.compositesa.2015.11.041.

[21] M. Engineering, K. H. Almitani, A. Wagih, A. Melaibari, and M. A. Eltaher, "Improving energy dissipation and damage resistance of CFRP laminates using alumina nanoparticles," Plast. Rubber Compos., vol. 0, no. 0, pp. 1-10, 2019, doi: 10.1080/14658011.2019.1591795.

[22] https://www.azom.com/properties.aspx?ArticleID=764, 2021.

[23] https://alcobrametals.com/aluminum-product-guide/, 2021. 